\title{
Clinical outcomes for patients with synovial sarcoma of the hand
}

\author{
Hidetatsu Outani ${ }^{* *}$, Kenichiro Hamada ${ }^{1}$, Kazuya Oshima ${ }^{2}$, Susumu Joyama ${ }^{2}$, Norifumi Naka', Nobuhito Araki ${ }^{2}$, \\ Takafumi Ueda ${ }^{3}$ and Hideki Yoshikawa ${ }^{1}$
}

\begin{abstract}
Purpose: Soft tissue sarcoma of the hand is rare, and one of the most common histological diagnosis is synovial sarcoma. We report the clinical outcomes of patients with synovial sarcoma of the hand and discuss treatment strategies.

Methods: We reviewed five patients with synovial sarcoma of the hand treated at our institutions from 1983 to 2013. The mean patient age at the time of diagnosis was 36.6 years (range, 20-62 years). Two patients underwent marginal excision after neoadjuvant chemotherapy, followed by radiation therapy, one underwent wide local excision and two received chemotherapy and radiation therapy.

Results: The average duration of follow-up for all patients was 88.2 months (range, 14-218 months). Two patients continuously remained disease free, two experienced local recurrence requiring additional surgery and then showed no evidence of disease, and one who had distant metastasis at diagnosis died of the disease. No patients developed lymph node metastasis. The estimated 5 -year overall survival was $80 \%$.

Conclusions: Our case series suggests that patients with localised synovial sarcoma of the hand may have favourable outcomes. Wide excision or marginal excision, followed by radiation therapy combined with chemotherapy, represent acceptable treatment strategies for synovial sarcoma of the hand. Regional lymph node dissection does not seem to be essential for synovial sarcoma of the hand.
\end{abstract}

Keywords: Synovial sarcoma; Soft tissue sarcoma; Hand; Hand preservation

\section{Introduction}

Soft tissue sarcoma of the hand is rare, with an incidence of approximately $2 \%-4 \%$ of limb and trunk tumours (Pradhan et al. 2008; McPhee et al. 1999). The histological types of soft tissue sarcoma in the hand are limited (Pradhan et al. 2008). The most frequent diagnoses are synovial sarcoma, clear cell sarcoma and epithelioid sarcoma (Pradhan et al. 2008; Brien et al. 1995; Puhaindran et al. 2011). Most sarcomas of the hand are currently treated with a multimodality strategy including limb-sparing surgery (Hsu et al. 2007). For epithelioid sarcoma, an exceptionally wide excision and regional lymph node dissection are recommended because of the increased risk of metastasis to the lymph nodes

\footnotetext{
* Correspondence: hidetatsu77@gmail.com

'Department of Orthopaedic Surgery, Osaka University Graduate School of Medicine, 2-2, Yamada-oka, Suita, Osaka 565-0871, Japan

Full list of author information is available at the end of the article
}

(Brien et al. 1995; Kawai et al. 2002). Pradhan et al. reported that clear cell sarcoma subtype is correlated with a poor survival rate due to the high risk of local recurrence (Pradhan et al. 2008). As mentioned above, the treatment strategy for soft tissue sarcoma of the hand may differ among tumour subtypes because of differences in local recurrence and metastatic potential. The purpose of this study was to review the clinical outcomes of patients with synovial sarcoma of the hand treated at our institutions, and to discuss appropriate treatment strategies for synovial sarcoma of the hand.

\section{Materials and methods}

We performed a retrospective review of all patients with a synovial sarcoma of the hand who were treated at our institutions over a period of 30 years from 1983 to 2013. Among 137 synovial sarcoma patients, five with a synovial sarcoma of the hand were identified from the 
institutional database (4\%). The clinical characteristics of the patients are summarised in Table 1 . All patients were male with the mean age of 36.6 years (range, 20-62 years), and all patients had tumours that were over the dorsum of the hand. All patients gave informed consent for their data to be included in this study. The ethical committee of our institute gave institutional review board approval to this retrospective study.

All patients were staged with computed tomography (CT) scanning of the chest and magnetic resonance imaging (MRI) of the hand. The American Joint Committee on Cancer (AJCC) staging system was used to stage the tumours (Greene et al. 2002). Three patients had AJCC stage IIA tumours, one had a stage IIB tumour and one had a stage IV tumour.

Two patients underwent biopsy at our institutions (Cases 3 and 4). Of these two patients, one was treated with marginal excision after neoadjuvant chemotherapy, followed by radiation therapy (Figure 1), and the other patient who had distant metastasis at diagnosis refused surgery and received chemotherapy and radiation therapy. Three patients underwent inappropriate surgical excisions without wide safety margins in another hospital and required further treatment (Cases 1,2 and 5). Of these three patients, one developed multiple local recurrences and underwent marginal excision to avoid hand amputation and preserve hand function after neoadjuvant chemotherapy followed by radiation therapy, one underwent wide excision with free tendon graft reconstruction, and the third refused surgery and received chemotherapy and radiation therapy. From 1983 to 1996, the chemotherapy regimen was dacarbazine, vincristine, nimustine, and interferon $\beta$ (dacarbazine, $140 \mathrm{mg} / \mathrm{m}^{2} /$ day over $1-5$ days; vincristine, $1.5 \mathrm{mg} / \mathrm{m}^{2}$ only on the first day; nimustine, $80 \mathrm{mg} / \mathrm{m}^{2}$ only on the first day and interferon $\beta, 6 \times 10^{6}$
U/day for 1-5 days). After 1997, the regimen was a combination of doxorubicin and ifosfamide (doxorubicin, $30 \mathrm{mg} /$ $\mathrm{m}^{2} /$ day for $1-2$ days and ifosfamide, $2.5 \mathrm{~g} / \mathrm{m}^{2} /$ day for $1-4$ days) or high-dose ifosfamide ( $3 \mathrm{~g} / \mathrm{m}^{2} /$ day for $1-5$ days).

\section{Results}

The average duration of follow-up for all patients was 88.2 months (range, 14-218 months). The presented symptoms included pain and swelling in one patient and swelling only in four patients. The mean duration of symptoms before diagnosis was 8.2 months (range, 1-12 months).

Two patients developed local recurrence, and both were treated with unplanned excisions at another hospital. One (Case 1) received repeated marginal excision to avoid hand amputation, followed by radiation therapy, and the other (Case 5) underwent double ray amputation after local recurrence, because the patient already had received radiation therapy and could not undergo marginal excision followed by radiation therapy (Figure 2). In addition, the latter patient developed metastasis to the lung after initial presentation and underwent pulmonary metastasectomy. No patients developed lymph node metastasis.

During the previous follow-up, two patients continuously remained disease free, two showed no evidence of disease after treatment for local recurrence and one died of distant metastases. The estimated 5-year overall survival was $80 \%$.

\section{Discussion}

Synovial sarcoma accounts for $5 \%-10 \%$ of all soft tissue sarcomas, frequently affecting adolescents and young adults and predominantly occurs in the extremities (Goldblum et al. 2013). Synovial sarcoma arising in the upper extremities, which accounts for approximately $10 \%-$ $15 \%$ of all cases, are fairly evenly distributed among the

Table 1 Patient summary

\begin{tabular}{|c|c|c|c|c|c|c|c|}
\hline Case/sex/age & Presentation & Location & Maximum dimension $(\mathrm{cm})$ & AJCC stage & CTx & RTx & Follow-up (months) \\
\hline $1 / M / 45$ & After previous surgery & Dorsum & 4 & $\| \mathrm{A}$ & Yes & Yes & 63 \\
\hline $2 / \mathrm{M} / 23$ & After previous surgery & Dorsum & 3 & $\| \mathrm{A}$ & No & No & 218 \\
\hline $3 / M / 62$ & Primary & Dorsum & 8 & $\| B$ & Yes & Yes & 43 \\
\hline $4 / M / 20$ & Primary & Dorsum & 6 & IV & Yes & Yes & 14 \\
\hline $5 / M / 33$ & After previous surgery & Dorsum & 3 & $\| \mathrm{A}$ & Yes & Yes & 103 \\
\hline Case & Procedure & Margins & \multicolumn{2}{|l|}{ Local recurrence } & \multicolumn{2}{|c|}{$\begin{array}{c}\text { Distant } \\
\text { metastases }\end{array}$} & Status \\
\hline 1 & Marginal excision & Negative & \multicolumn{2}{|l|}{ Yes } & \multicolumn{2}{|c|}{ No } & NED \\
\hline 2 & Wide excision with free tendon graft & Negative & \multicolumn{2}{|l|}{ No } & \multicolumn{2}{|c|}{ No } & CDF \\
\hline 3 & Marginal excision with IORTG & Negative & \multicolumn{2}{|l|}{ No } & \multicolumn{2}{|c|}{ No } & CDF \\
\hline 4 & No operation & - & \multicolumn{2}{|l|}{ (Persistent disease) } & \multicolumn{2}{|c|}{ Yes } & DOD \\
\hline 5 & ${ }^{*}$ Double ray amputation & Negative & \multicolumn{2}{|l|}{ Yes } & \multicolumn{2}{|c|}{ Yes } & NED \\
\hline
\end{tabular}

CTx, chemotherapy; RTx, radiation therapy.

NED, no evidence of disease; CDF, continuous disease free; DOD, dead of disease; IORTG, intraoperative extracorporeal autogenous irradiated tendon grafts; *operation was performed after local recurrence. 

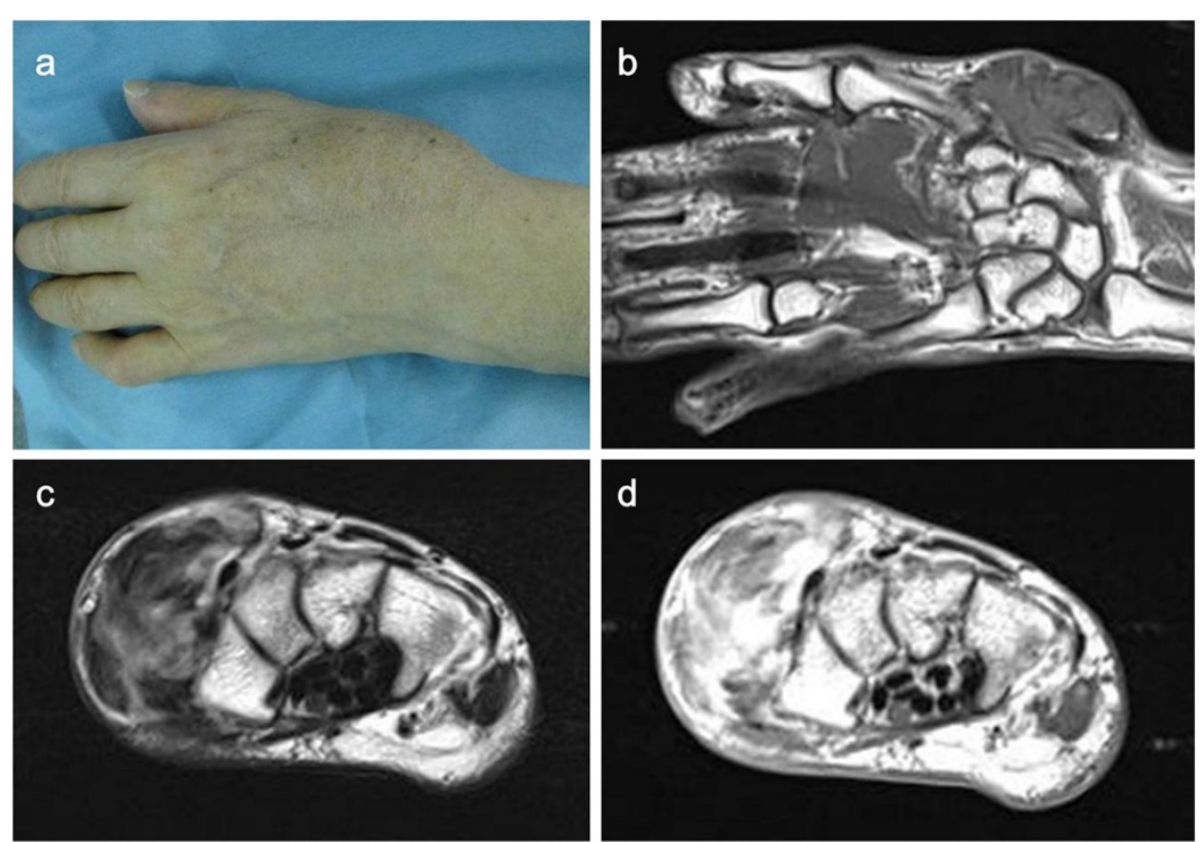

Figure 1 Representative case: case 3. (a) A 62-year-old male patient with synovial sarcoma in the dorsoradial aspect of the hand. (b) Magnetic resonance imaging (MRI) of the tumour showed isointensity on a T1 image, (c) inhomogeneous high on a T2 image and (d) enhancement with the use of gadolinium. The mass spanned the first, second and third compartments of the extensor tendon sheath but with no evidence of bone involvement.

forearm-wrist region, shoulder, elbow-upper arm region and hand (Goldblum et al. 2013). In our study, 4\% of synovial sarcomas were observed in the hand, and this incidence is similar to that of all extremity-related sarcomas (Pradhan et al. 2008; McPhee et al. 1999).
The typical presentation of synovial sarcoma of the hand is a slow-growing mass. Because of the rarity of the soft tissue sarcoma of the hand, $38 \%-95 \%$ of these tumours are treated by unplanned excision before referral to a specialist oncological center (Pradhan et al. 2008; Lin et al. 2002).
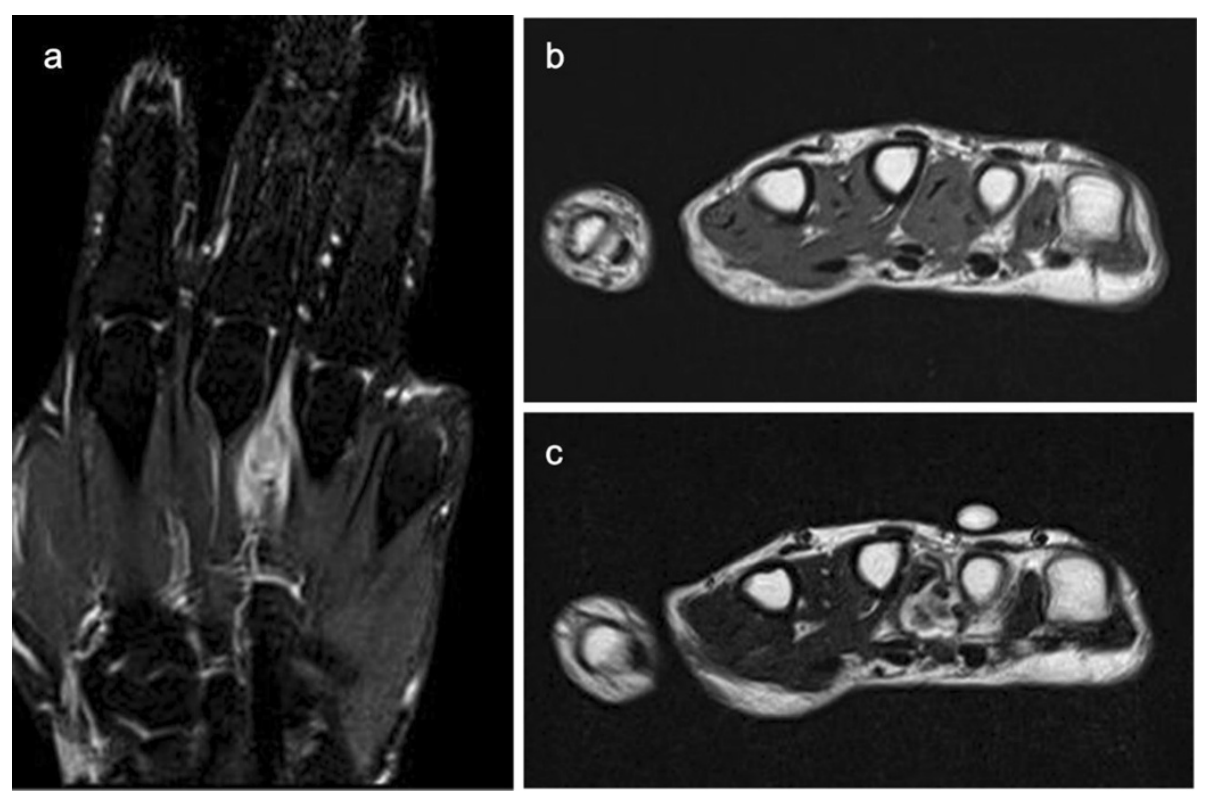

Figure 2 Recurrent synovial sarcoma in the dorsum of the hand: case 5. (a) MRI of the tumour showed high intensity on T1 fat sat image, (b) isointensity on a T1 image and (c) high intensity on a T2 image. The mass spanned the third and fourth metacarpal bones. 
Pradhan et al. reported that no significant correlation exists between previous surgical excision and the risk of local recurrence or overall survival (Pradhan et al. 2008). However, Talbot et al. reported that an unplanned excision represents a larger operation requiring flap coverage in affected patients (Talbot et al. 2008). In the present report, three of the five patients had been treated with an unplanned excision. One of the three patients underwent free tendon graft reconstruction, but no patients required flap coverage. Moreover, all of these three patients experienced a favourable outcome after multimodal treatment. In cases of large skin defects after surgical excision, skin grafting and flap coverage are important options. The radial forearm flap and the reversed radial forearm flap can be used to effectively cover large soft tissue defects in the hand (Talbot et al. 2008; Ferguson 2005). Tendons can often be resected with the tumours and reconstructed with free tendon grafts from the palmaris longus. However, when multiple tendons were surrounded by the tumours, we previously re-implanted intraoperative extracorporeal autogenous irradiated tendon grafts to restore hand function (Araki et al. 1999).

Because of its complex anatomy and limited tissue volume, soft tissue sarcoma of the hand has a tendency to rapidly spread between compartments which makes excision with a wide margin difficult (Pradhan et al. 2008; Kawai et al. 2002). Unfortunately, the minimal acceptable margin has not been established (Siegel et al. 2007). Talbert et al. reported the lack of a survival benefit from amputation in patients with soft tissue sarcoma of the distal extremities and recommended conservation surgery and radiation therapy (Talbert et al. 1990). In contrast, Brien et al. reported that adjuvant radiotherapy could not compensate for positive surgical margins (Brien et al. 1995). Two independent investigators emphasised the importance of negative surgical margins for local control and prevention of metastatic disease (Pradhan et al. 2008; Puhaindran et al. 2011). However, those studies included various tumour sub-types. Few reports have focused on synovial sarcoma of the hand (Dreyfuss et al. 1986; Michal et al. 2006), and the best treatment strategy for synovial sarcoma of the hand remains unknown. Synovial sarcoma is relatively chemosensitive (Canter et al. 2008; Rosen et al. 1994). Therefore, our approach has been to perform marginal excision, avoiding amputation of the entire hand, followed by radiation therapy combined with chemotherapy to preserve hand function and to reduce the risk of local recurrence or distant failure when it is difficult to achieve wide local excision. However, we assume that amputation is still required when an important neurovascular structure cannot be preserved or when local recurrence has occurred after postoperative radiotherapy. Some authors have reported the importance of regional lymph node dissection for some sub-types of sarcoma of the hand (Brien et al. 1995; Kawai et al. 2002). Although the small number of patients is a limitation of the present study, no patients developed lymph node metastasis in this study. In a previous case series, Brien et al. described the clinical features of soft tissue sarcoma of the hand (Brien et al. 1995), and of the 23 patients in that series, 8 had synovial sarcomas and none of them developed lymph node metastasis. Therefore, we believe that regional lymph node dissection is not essential for patients with synovial sarcoma of the hand.

The favourability of prognosis in patients with synovial sarcoma of the hand is controversial. Canter et al. reviewed 255 patients with localised synovial sarcoma of all anatomic sites and reported a 5-year disease-specific survival of $72 \%$; an upper extremity location was associated with favourable prognosis (Canter et al. 2008). Dreyfuss et al. reviewed 44 cases of synovial sarcoma of the hand that were treated over the period from 1934 to 1984 and reported a 5-year overall survival of only $18 \%$ (Dreyfuss et al. 1986). However, of those 44 cases, 13 patients $(30 \%)$ were treated with radiation therapy and only two patients $(5 \%)$ were treated with chemotherapy. In our previous 30-year series, the estimated 5-year overall survival was $80 \%$. Improvements in pre-operative imaging and adjuvant therapies may have contributed to patient survival in our current series.

In conclusion, we report five cases of synovial sarcoma of the hand. The clinical outcomes of synovial sarcoma of the hand were favourable when distant metastasis was not present at diagnosis. Patient survival was similar to that for synovial sarcoma in all locations. Wide excision or marginal excision, followed by radiation therapy combined with chemotherapy, are acceptable treatment strategies for synovial sarcoma of the hand. Regional lymph node dissection does not seem to be essential for synovial sarcoma of the hand.

\section{Competing interests}

The authors declare that they have no competing interests.

\section{Authors' contributions}

$\mathrm{HO}$ and $\mathrm{KH}$ conceived and designed the study. $\mathrm{HO}$ collected and interpreted the data, wrote the manuscript, and provided final approval. KO, SJ, NN, NA

TU and HY participated in the discussion of the results and reviewing the manuscript. All authors read and approved the final manuscript.

\section{Funding statement}

This research received no specific grant from any funding agency in the public, commercial, or not-for-profit sectors.

\section{Author details}

Department of Orthopaedic Surgery, Osaka University Graduate School of Medicine, 2-2, Yamada-oka, Suita, Osaka 565-0871, Japan. ${ }^{2}$ Musculoskeletal Oncology Service, Osaka Medical Center for Cancer and Cardiovascular Diseases, 1-3-3 Nakamichi, Higashiknari, Osaka 537-8511, Japan. ${ }^{3}$ Department of Orthopaedic Surgery, Osaka National Hospital, 2-1-14 Hoenzaka, Chuo-ku, Osaka 540-0006, Japan. 


\section{References}

Araki N, Myoui A, Kuratsu S, Hashimoto N, Inoue T, Kudawara I, Ueda T, Yoshikawa H, Masaki N, Uchida A (1999) Intraoperative extracorporeal autogenous irradiated bone grafts in tumor surgery. Clin Orthop Relat Res 368:196-206

Brien EW, Terek RM, Geer RJ, Caldwell G, Brennan MF, Healey JH (1995) Treatment of soft-tissue sarcoma of the hand. J Bone Joint Surg 77A:564-571

Canter RJ, Qin LX, Maki RG, Brennan MF, Ladanyi M, Singer S (2008) A synovial sarcoma-specific preoperative nomogram supports a survival benefit to Ifosfamid-based chemotherapy and improves risk stratification for patients. Clin Cancer Res 14:8191-8197

Dreyfuss UY, Boome RS, Kranold DH (1986) Synovial sarcoma of the hand-a literature study. J Bone Joint Surg Br 11:471-474

Ferguson PC (2005) Surgical considerations for management of distal extremity soft tissue sarcoma. Curr Opin Oncol 17:366-369

Goldblum JR, Flope AL, Weiss SW (2013) Malignant soft tissue tumors of uncertain type. In: Enzinger \& Weiss's Soft Tissue Tumors, 6th edn. Elsevier, Philadelphia, pp 1052-1070

Greene FL, Page DL, Fleming ID, Fritz AG, Balch CM, Haller DG (2002) American Joint Committee on Cancer: Cancer Staging Manual, 6th edn. Springer, New York, pp 221-226

Hsu CS, Hentz VR, Yao J (2007) Tumours of the hand. Lancet Oncol 8:157-166

Kawai A, Hasizume H, Sugihara S, Morimoto Y, Inoue H (2002) Treatment of bone and soft tissue sarcomas of the hand and wrist. Int Orthop 26:26-30

Lin PP, Guzel VB, Pisters PW, Zagars GK, Weber KL, Feig BW, Pollock RE, Yasko AW (2002) Surgical management of soft tissue sarcomas of the hand and foot. Cancer 95:852-861

McPhee M, McGrath BE, Zhang P, Driscoll D, Gibbs J, Peimer C (1999) Soft tissue sarcoma of the hand. J Hnad Surg 24A:1001-1007

Michal M, Fanburg-Smith JC, Lasota J, Fetsch JF, Lichy J, Miettinen M (2006) Minute synovial sarcomas of the hand and feet; a clinicopathologic study of 21 tumors less than $1 \mathrm{~cm}$. Am J Surg Pathol 30:721-726

Pradhan A, Cheung YC, Grimmer RJ, Peake D, Al-Muderis OA, Thomas JM, Smith M (2008) Soft-tissue sarcomas of the hand: oncological outcome and prognostic factors. J Bone Joint Surg [Br] 90-B:209-214

Puhaindran ME, Rohde RS, Chou J, Morris CD, Athanasian EA (2011) Clinical outcomes for patients with soft tissue sarcoma of the hand. Cancer 117:175-179

Rosen G, Forscher C, Lowenbraun S, Elber F, Eckardt J, Holmes C, Fu YS (1994) Synovial sarcoma: uniform response of metastases to high dose ifosfamide. Cancer 73:2506-2511

Siegel HJ, Sessions W, Casillas MA Jr, Said-Al-Naief N, Lander PH, Lopez-Ben R (2007) Synovial sarcoma: clinicopathologic features, treatment, and prognosis. Orthopedics 30:1020-1027

Talbert ML, Zagars GK, Sherman NE, Romsdahl MM (1990) Conservative surgery and radiation therapy for soft tissue sarcoma of the wrist, hand, ankle, and foot. Cancer 66:2482-2491

Talbot SG, Mehrara BJ, Disa JJ, Wong AK, Pusic A, Cordeiro PG, Athanasian EA (2008) Soft-tissue coverage of the hand following sarcoma resection. Plast Reconstr Surg 121:534-543

\section{doi:10.1186/2193-1801-3-649}

Cite this article as: Outani et al: Clinical outcomes for patients with synovial sarcoma of the hand. SpringerPlus 2014 3:649.

\section{Submit your manuscript to a SpringerOpen ${ }^{\odot}$ journal and benefit from:}

- Convenient online submission

- Rigorous peer review

- Immediate publication on acceptance

- Open access: articles freely available online

- High visibility within the field

- Retaining the copyright to your article

Submit your next manuscript at $>$ springeropen.com 